Article

\title{
Wireless Sensor Network Powered by a Terrestrial Microbial Fuel Cell as a Sustainable Land Monitoring Energy System
}

\author{
Andrea Pietrelli ${ }^{1}$, Andrea Micangeli ${ }^{2,3, *}$, Vincenzo Ferrara ${ }^{1}$ and Alessandro Raffi ${ }^{3}$ \\ 1 Department of Information Engineering, Electronics and Telecommunications (DIET), \\ Sapienza University of Rome, Via Eudossiana 18, Rome 00184, Italy; \\ E-Mails: andrea.pietrelli@libero.it (A.P.); vincenzo.ferrara@uniroma1.it (V.F.) \\ 2 Department of Mechanical and Aerospace Engineering, Sapienza University of Rome, \\ Via Eudossiana 18, Rome 00184, Italy \\ 3 Interuniversity Research Center on Sustainable Development (CIRPS), Sapienza University of \\ Rome, Via Cavour 256, Rome 00184, Italy; E-Mail: ing.alessandro.raffi@gmail.com \\ * Author to whom correspondence should be addressed; E-Mail: andrea.micangeli@uniroma1.it; \\ Tel.: +39-338-815-3787; Fax: +39-06-8745-2050.
}

External Editor: Marc A. Rosen

Received: 31 July 2014; in revised form: 25 September 2014 / Accepted: 26 September 2014 /

Published: 22 October 2014

\begin{abstract}
This work aims at investigating the possibility of a wireless sensor network powered by an energy harvesting technology, such as a microbial fuel cell (MFC). An MFC is a bioreactor that transforms energy stored in chemical bonds of organic compounds into electrical energy. This process takes place through catalytic reactions of microorganisms under anaerobic conditions. An anode chamber together with a cathode chamber composes a conventional MFC reactor. The protons generated in the anode chamber are then transferred into the cathode chamber through a proton exchange membrane (PEM). A possible option is to use the soil itself as the membrane. In this case, we are referring to, more properly, a terrestrial microbial fuel cell (TMFC). This research examines the sustainability of a wireless sensor network powered by TMFC for land monitoring and precision agriculture. Acting on several factors, such as $\mathrm{pH}$, temperature, humidity and type of soil used, we obtained minimum performance requirements in terms of the output power of the TMFC. In order to identify some of the different network node configurations and to compare the resulting performance, we investigated the energy consumption of the core components of a node, e.g., the transceiver and microcontroller, looking for the best performance.
\end{abstract}


Keywords: energy harvesting; microbial fuel cell; land monitoring; precision agriculture; low-power electronics

\section{Introduction}

This research investigates the possibility of a wireless sensor network powered by terrestrial microbial fuel cells (TMFCs) [1] for land monitoring and for precision agriculture.

The work examines the sustainability of a sensor network powered by TMFCs. These network nodes are distributed throughout an area, for monitoring the territory, and are an alternative to remote sensing systems. At first, we will obtain minimum performance requirements in terms of the output power of a TMFC, acting on several factors, such as $\mathrm{pH}$, temperature, humidity and type of soil used, and then, we will try to search for a better configuration for a single node. In order to identify some of the different network node configurations and to compare the resulting performance, we investigated the energy consumption of the core components of a node, e.g., transceiver and microcontroller, looking for the best performance.

\subsection{Microbial Fuel Cell}

The technology described and investigated in this review is based on an MFC reactor [2]. This one is composed of two cells, each of which includes an electrode, named respectively: the anode and cathode. The anode is placed in a nutrient-enriched environment and under strictly anaerobic conditions, while the cathode is exposed to oxygen. Each electrode is connected with the other forming an electrically-closed circuit through a resistor. The system is based on oxidation and reduction-coupled reactions: the oxidation occurs in the anode producing electrons, which are then reduced in the cathode. The reactions are electrically separated, forcing electrons to flow through an external circuit, while the movement of $\mathrm{H}$-ions from the anode to the cathode in the system maintains the balance of electrical charges and completes the circuit.

A semipermeable proton exchange membrane (PEM) can divide the two chambers, in order to keep them physically separated in two environments, the anode and cathode, and to assure the passage of protons. However, there are systems in which the use of a PEM is not considered; they are called membrane-less, in which a material of a different nature connects the compartments. In the case of TMFCs, it is the ground itself that plays the roles of both the PEM and the source of biodegradable organic matter for the purposes of power generation. The anode chamber is kept under anaerobic conditions, ideal for ensuring the development and proliferation of bacteria, which adhere to the electrode by forming a biofilm. Located at this electrode, microorganisms degrade the organic matter, producing electrons, protons and carbon dioxide [3]. The protons, a by-product of electrogenic metabolism, transferred to the cathode, react together with oxygen, forming water molecules. In detail, it is possible to observe the reactions occurring within a cell using acetate as a substrate:

$$
\begin{gathered}
\text { Anodic reaction: } \quad \mathrm{CH}_{3} \mathrm{COOH}+2 \mathrm{H}_{2} \mathrm{O} \rightarrow 2 \mathrm{CO}_{2}+8 \mathrm{H}^{+}+8 \mathrm{e}^{-} \\
\text {Cathodic reaction: } \quad 2 \mathrm{O}_{2}+8 \mathrm{H}^{+}+8 \mathrm{e}^{-} \rightarrow 4 \mathrm{H}_{2} \mathrm{O}
\end{gathered}
$$


The carbon dioxide is generated as a product of oxidation. However, there are no net carbon emissions into the atmosphere, because the $\mathrm{CO}_{2}$ produced is biogenic, which is included in the biogeochemical carbon cycle.

Compared to traditional inorganic fuel cells, which use energy generated from fossil fuel conversion, an MFC bases its operational mode on biofuel and biocatalyst as the essential elements: they therefore represent a fully sustainable zero emissions technology. Microorganisms are the most common biocatalysts used in this technology as a consequence of both their wide diffusion in the biosphere and the ability to self-sustain of some microbial species. Particularly for the latter feature, the production of energy by an MFC is continuous, and it is limited only by the availability of nutrients within the anode support. The bioelectricity obtained from the work of microorganisms has been known since the beginning of the last century, but has become topical only recently. The transfer mechanism of electrons into the cell can occur in three different ways: direct transfer from the molecule to the anode surface; transfer of electrons through external mediators, employing a secondary biomolecule that carries electrons to the anode (e.g., Pseudomonas aeruginosa, which produces the pyocyanin); and finally, electrons transfer through bacterial appendages, named nano-wires.

The most interesting class of bacteria is one that can produce electricity without requiring the addition of mediators. Known as electrogenic species, these bacteria directly transfer electrons to chemical species or a substance that is not an immediate electron-acceptor. Among the major strains of electrogenic bacteria, we can count Geobacter metallireducens, Geobacter sulfurreducens [4] and Desulfuromonas acetoxidans in the family of Geobacteraceae, while among Shewanella, we mention Shewanella putrefaciens [5] and Shewanella oneidensis [6]. The MFC voltage is determined by the difference in redox potential between the two distinct electrodes. Redox potential discloses the tendency of a chemical species to be reduced, that is to acquire electrons. Its value is expressed in volts (V). Redox potential is therefore an intrinsic feature of the electrogenic chemical species: the higher the value, the higher is the electron affinity and the bigger is its tendency to be reduced.

When a microbial community forms and begins to respire at the anode surface, the highly reduced biomolecules start to accumulate around the anode. This build-up of metabolic by-products decreases the electrical potential of the anode, settling on values typically between $-0.4 \mathrm{~V}$ and $-0.1 \mathrm{~V} v s$. SHE (standard hydrogen electrode).

The presence of oxygen moves the electrical potential of the cathode to a higher value, typically from $0.4 \mathrm{~V}$ to $0.8 \mathrm{~V} v$ s. SHE. The working voltage of the MFC is merely the potential of the anode subtracted from the potential of the cathode. It should be noted that MFCs have a theoretical maximum voltage, approximately $1.2 \mathrm{~V}$ between the two electrodes, since the redox potential of reduced biomolecules has a minimum of $-0.4 \mathrm{~V} v s$. SHE and the redox potential of oxygen is $0.8 \mathrm{~V} v s$. SHE [1]. However, the laboratory performance of MFCs is still much lower than the ideal performance. The production of energy in an MFC is function of numerous factors, such as the possible geometries of the system and the types of involved bacteria. The present work analyzes the main operating parameters influencing the overall performance of a TMFC system. The parameters mainly observed are: $\mathrm{pH}$ and temperature, which directly influence the microbial metabolic activities; the water content, which influences the diffusion of both the nutrients and of the protons; the type of biomass and substrate used; and the electrode materials and its surface area. 


\subsection{Different Types of Microbial Fuel Cells}

There are different type of MFCs; one is named the terrestrial microbial fuel cell (TMFC) and is founded on the same basic MFC principles described above; whereby, standard topsoil is the nutrient-rich anodic medium, the inoculum and the proton-exchange membrane (PEM).

The anode is placed at a working depth, generally about $8 \mathrm{~cm}$ into the ground, while the cathode is preferable on top of the soil, in order to expose it to the oxygen in the air. Located in the soil, the aerobic microbes act as an oxygen filter, consuming oxygen and, thus, preventing infiltration into the anode compartment. The typical electrical potentials achieved in TMFCs are $0.2 \mathrm{~V}$ to $0.6 \mathrm{~V} v s$. SHE for the cathode and in a range from $-0.2 \mathrm{~V}$ to $0.0 \mathrm{~V} v s$. SHE for the anode [1]. Therefore, the theoretical maximum voltage of TMFC that can be achieved between the two electrodes is approximately $0.8 \mathrm{~V}$.

Moreover, there are some different types of MFCs, like benthic or plant. In the first case of benthic MFCs, ocean sediment acts as the nutrient-rich anodic media, the inoculum and the proton-exchange membrane (PEM), the anodic redox potential typically leveling at approximately $-0.4 \mathrm{~V} v \mathrm{~s}$. SHE. The cathode may still exhibit a potential of $0.4 \mathrm{~V} v \mathrm{~s}$. SHE at depths in excess of $950 \mathrm{~m}$ [7].

In the second case, living plants transport substantial amounts of organic material into the soil. This process, called rhizodeposition, provides the substrate for the rhizospheric microbial community. An example is an MFC planted with rice, which is capable of reaching in an open circuit $0.8 \mathrm{~V}$ with an anodic redox potential of $-0.34 \mathrm{~V} v s$. SHE. [8]

\section{Experimental Section}

This work is divided into two parts. The first one concerns the experiments, conducted in the laboratories of the Center of Agronomical Research of the University of Costa Rica, assessing the good performance, in terms of the power production, of the TMFC. We will provide the specifics about the construction scheme of the reactor and about the measurement methods. The second part, conducted at the Sapienza University of Rome, focuses on the electronic components of the nodes of the network. A comparison of the performances of the different configurations adopted for the node was conducted in order to find an innovative solution for the monitoring of key parameters [9-14].

\subsection{Construction of Terrestrial Microbial Fuel Cells}

Cells were built in PVC cylindrical reactors, with a diameter of $10 \mathrm{~cm}$ and a height of $10 \mathrm{~cm}$ (Figure 1). During the experiment, two different types of reactors were employed: closed reactors and open reactors.

Closed reactors, of course, impose opportune and stable boundary conditions, optimizing the process parameters and, consequently, the final energy production.

The materials chosen for the electrodes must be chemically inert, electrically conductive and have a large surface area, so as to increase the contact area between the electrode and the microbial community in the case of the anode and the reaction surface with oxygen in the case of the cathode. In the trial phase, the electrodes used were made from fiber graphite felt (a ratio of the surface-to-mass of about $0.47 \mathrm{~m}^{2} / \mathrm{g}$ ), obtaining circular elements of a diameter of about $9.2 \mathrm{~cm}$, a thickness of about $0.65 \mathrm{~cm}$ and a surface area of $0.057 \mathrm{~m}^{2}$. 
Instead, the cables were made of titanium and coated with an insulating material, protecting them from electrical interference caused by other components. These titanium cables were inserted into the disks, for connecting electrodes.

Finally, a resistor is mounted on a KeegoTech board and placed on the upper side of the reactor, completing the equipment. The graph displaying the evaluation of the power produced by the reactors has been carried out by using six different resistors, respectively of the following values: 47, 100, 220, 470,1000 and 10,000 Ohm. In performing the measurements, the voltage was checked thirty minutes after the insertion of each resistance, allowing for the stabilization of the voltage.

Figure 1. Construction scheme of the reactor.

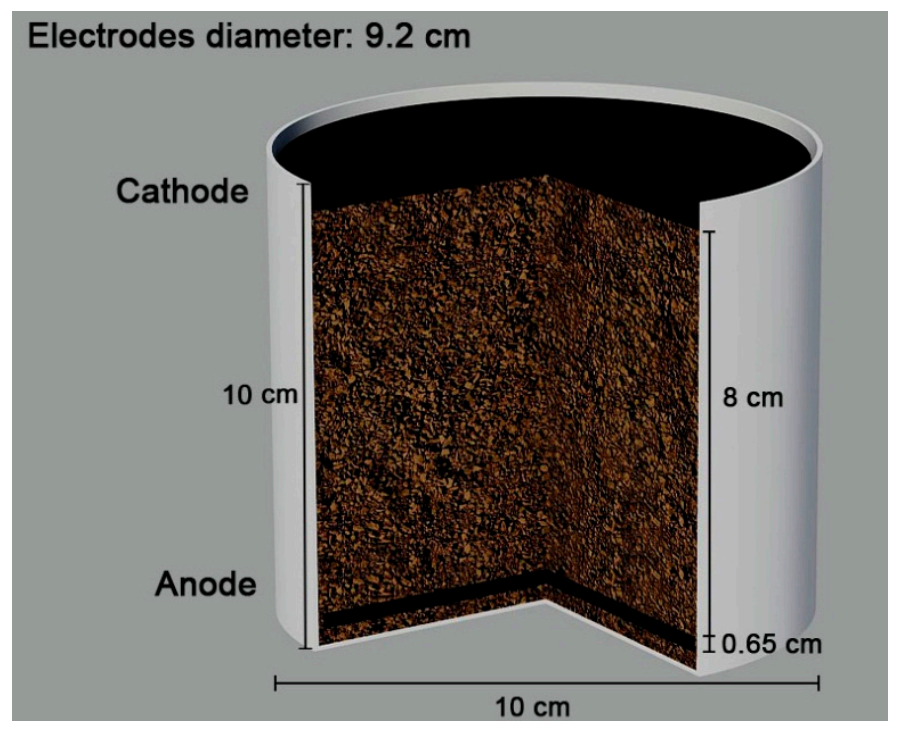

\subsection{Temperature, Humidity and $p H$ Analysis}

In order to evaluate the influence of temperature on the energy yield of the reactors, some of them were left subject to the daily temperature, while for others, it was decided to study their performance at set temperature values. To control the temperature and adjust it to the desired value, the specimens were placed in special incubators. The temperature was monitored throughout the day using a multimeter equipped with a thermocouple.

To keep the $\mathrm{pH}$ under control in the course of the experiment, a $\mathrm{pH}$ meter (made by Hanna Instruments) equipped with a glass electrode was used.

Humidity control was performed by the gravimetric method.

$$
\% \text { Total Humidity }=\frac{\text { wet weight }- \text { dry weight }}{\text { dry weight }} \times 100
$$

\subsection{Voltage Produced and Power Generated}

The power was measured daily with a digital multimeter (ProsKit MT-1210) to evaluate performance.

The meter used for measuring the potential power supply has also been used for the reconstruction of power curves. An MFC generates the maximum power when the external resistance is equal to its internal resistance. The resistance offered by the soil is precisely the internal resistance of the system, 
which can be assessed by means of appropriate power tests. The calculation method used is based on Ohm's law. From the reconstruction of the curve, you can identify the peak maximum power, which corresponds to the value of the internal resistance offered by the system. Again, according to Ohm's law, and by knowing the value of the delivered power together with the resistor used and the voltage measured, it was possible to calculate the corresponding value of the current.

\subsection{Wireless Node Configuration}

A single node of a wireless network necessarily includes the presence of a transceiver for communication and a microcontroller for the management of information. These elements require an amount of electrical current intensity for the operation at a typical voltage of $3.3 \mathrm{~V}$. TMFC generally delivers a current intensity and voltage lower than those necessary for the operation of these components. In order to achieve adequate levels of current and voltage, an interface circuit is needed to increase the voltage level and to accumulate the amount of current required.

\section{Results and Discussion}

\subsection{Description of the Experimental Stages}

The test phase can be divided into three main steps. The first test phase assessed the effect of $\mathrm{pH}$ on TMFCs using a soil with characteristics typical of those found in Central America with a pH of 5.3. The results were compared with those of a soil with a higher $\mathrm{pH}$ of 6.3 . The second phase aims at highlighting the specific influence of microorganisms, in terms of energy production. This experimental phase consists of the inoculation of the microorganism, the most monitored in the previous phase, in a previously sterilized soil. The third and final step describes the results achieved with a basic $\mathrm{pH}$ and nutrient-rich soil. The following Table 1 shows a schematic description of the experimental phases. In all experimental phases, we used five specimens in total (labeled in the following as A, B, C, D, E), and for each of the five, three independent biological replicates were provided. The values in the Table 2, for each of the five specimens are the statistical average of the results obtained in each of the three independent replicates.

Table 1. Description of the composition of the specimens and setup conditions.

\begin{tabular}{cccccccc}
\hline & Specimens & $\begin{array}{c}\text { Reactors } \\
\text { Configuration }\end{array}$ & $\begin{array}{c}\text { Soil } \\
\text { Volume (g) }\end{array}$ & $\mathbf{p H}$ & $\begin{array}{c}\text { Controlled } \\
\text { Temperature }\end{array}$ & $\begin{array}{c}\text { Initial } \\
\text { Humidity (\%) }\end{array}$ & $\begin{array}{c}\text { Final } \\
\text { Humidity (\%) }\end{array}$ \\
\hline \multirow{2}{*}{ Phase 1 } & A & Open & 260 & 5.3 & No & 34.62 & 33.57 \\
& B & Open & 260 & 6.3 & No & 35.85 & 30.88 \\
\hline \multirow{2}{*}{ Phase 2 } & C & Closed & 260 & 6.3 & Yes & 35.1 & 35.1 \\
\hline Phase 3 & D & Closed & 260 & 6.3 & Yes & 34.8 & 34.5 \\
\hline
\end{tabular}


Table 2. Results obtained for each specimen.

\begin{tabular}{ccccccc}
\hline Specimen & $\begin{array}{c}\text { Specimen } \\
\text { Length } \\
\text { (Days) }\end{array}$ & $\begin{array}{c}\text { Maximum } \\
\text { Voltage } \\
\text { Produced }(\mathbf{m V})\end{array}$ & $\begin{array}{c}\text { Average } \\
\text { Voltage } \\
(\mathbf{m V})\end{array}$ & $\begin{array}{c}\text { Maximum } \\
\text { Power } \\
\text { Produced }(\boldsymbol{\mu W})\end{array}$ & $\begin{array}{c}\text { Normalized Anode } \\
\text { Surface Maximum } \\
\text { Power }\left(\mathbf{m} \mathbf{W} / \mathbf{m}^{2}\right)\end{array}$ \\
\hline \multirow{2}{*}{ Phase 1 } & A & 14 & 154.4 & 72.91 & 0.30 & 0.04 \\
& $\mathbf{B}$ & 30 & 192.3 & 160.27 & 10.44 & 1.57 \\
\hline \multirow{2}{*}{ Phase 2 } & $\mathbf{C}$ & 45 & 327 & 293.42 & 34.04 & 5.11 \\
& $\mathbf{D}$ & 45 & 368 & 325.26 & 41.33 & 6.2 \\
\hline Phase 3 & E & 65 & 662 & 590.1 & 310.24 & 46.58 \\
\hline
\end{tabular}

\subsubsection{First Experimental Cycle: Specimens A and B}

The first phase of the experiment confirmed the unsuitability of this technology to acid soils. In the graph of Figure 2, concerning the potential, "Test Specimen A" shows a bell-shaped trend. This confirms a good increase of the voltage produced by the cell during the first week of operation. Unfortunately, the same graph shows evidence following a rapid fall of the potential until its complete zeroing. This trend is due to the low $\mathrm{pH}$ value of the soil. In the initial phase, it is not limiting, but during the degradation activity of the substrate, showing the production of the strongly acid catabolites, the $\mathrm{pH}$ is lowered further, reaching a value below the range of tolerance of the bacteria themselves. With these premises, the power curve calculated obviously shows absolutely unsatisfactory and unusable values.

Figure 2. Evolution of the open circuit potential obtained in the experimental stages.

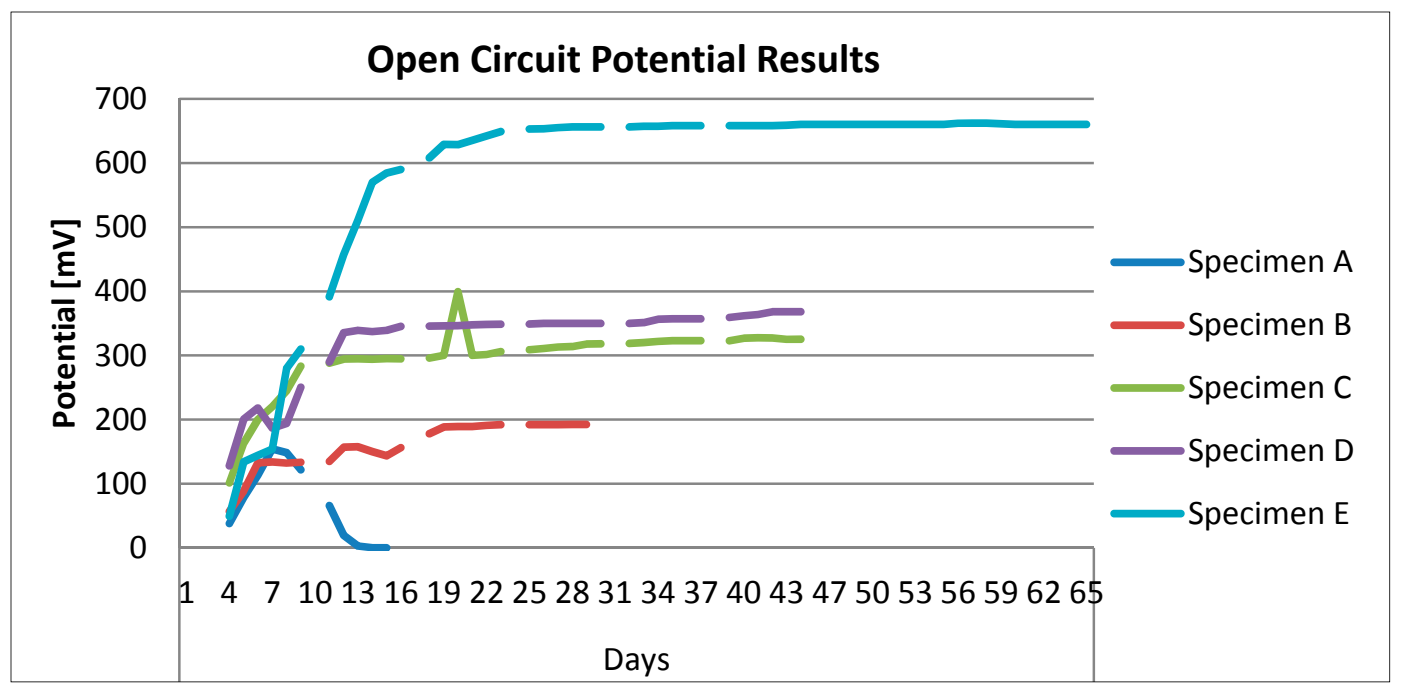

The results obtained improve significantly with the second sample " $\mathrm{B}$ " monitored during the first phase of the trial. Next, in order to obtain more meaningful data, a clay soil with a $\mathrm{pH}$ value of 6.3 was used. First, you have to show the duration and stability of the specimen, which, after an initial phase of growth, lasting approximately two weeks, has stabilized to an output voltage of around $200 \mathrm{mV}$, as is observable in the related graph of Figure 2. The energy production of the samples remained constant throughout the entire period of one month. The power curve shows significantly higher values than those obtained from Specimen A. It is noted that both samples were prepared in the same way, and the experimentation took place under the same operating conditions. 


\subsubsection{Second Experimental Cycle: Specimens C and D}

The results obtained during the first phase of the experiment made it possible to narrow the range of applicability of the technology, the conditioning from the $\mathrm{pH}$ parameter, by testing the sample cell with different soils characterized by $\mathrm{pH}$ progressively tending to neutrality, and excluding the soil showing a $\mathrm{pH}$ of 5.3, which was used in the Specimen A.

In the second experimental cycle, two samples with a soil characterized by a $\mathrm{pH}$ of 6.3 were employed. Furthermore, it was decided to modify the configuration of the reactors, so as to be able to work with a closed system, and to better control the other two main operating parameters, i.e., temperature and water content. To counter the very irregular temperature trend, observed during the first experimental phase, an incubator was used, imposing a constant temperature of $26{ }^{\circ} \mathrm{C}$. Specimen B had showed, after one month of operation, a sharp decrease of water content, linked to the phenomena of evaporation. The new configuration of the reactors has allowed, in this case, a stable moisture value next to its initial amount, by the time that in the closed system, all of the water that evaporates is destined to re-condense. With the fixed amounts of $\mathrm{pH}$, humidity and temperature, it was decided to evaluate the different behavior of the two samples, in two different operating conditions: the first in the presence of an inoculated single bacterial strain and the second in standard conditions. The inoculation of the bacterium occurred after autoclave sterilization of the soil used.

The results obtained in this phase of the research were positive, rewarding the operational choices that were made. Both samples have ensured a stable operation for the whole duration of the experimental cycle (45 days). After the period of growth, classically lasting about ten days, the position of the electrical potential values was stably around their maximum values, showing variations of less than 5\%. Comparing the performance of two specimens, this can highlight a slight superiority of "Specimen D", the only one of the five specimens achieved with the inoculated Pseudomonas bacterial strain. The level of the output voltage exceeded the $12.5 \%$ recorded by "Sample C". The maximum power obtained from Sample C, normalized to the surface of the anode, is $5.11 \mathrm{~mW} / \mathrm{m}^{2}$. On the other hand, Specimen D reached a power value of $6.2 \mathrm{~mW} / \mathrm{m}^{2}$.

\subsubsection{Third Experimental Cycle: Specimen E}

Next, we used a peaty soil, characterized by a value of $\mathrm{pH}=7.2$, and as expected, we confirmed this to be a decisive factor for optimizing the performance of this kind of MFC. The samples were again placed inside the incubator, initially at a temperature of $24^{\circ} \mathrm{C}$. Subsequently, when the performance of the cell was stabilized, the temperature was raised to $26^{\circ} \mathrm{C}$ (Day 42), in such a way so as to assess whether the increase in temperature could affect the production of energy. Again, following the stabilization of the output voltage from the cell, a second temperature increase of $28{ }^{\circ} \mathrm{C}$ was made on Day 55. From the analysis of the graph (Figure 2), it is evident that the increases in temperature has had a limited influence on the performance of the cell: these gradual increases produced in fact, a growth of the electrical potential of $0.3 \%$. The maximum power production (Table 3 ), in correspondence with a resistance of $1000 \mathrm{ohms}$, is equal to $0.31 \mathrm{~mW}$ (Figure 3), which corresponds to a current intensity of $0.557 \mathrm{~mA}$. Instead, when we normalized the power produced on the surface of the anode, a power density of $46.58 \mathrm{~mW} / \mathrm{m}^{2}$ has been obtained. This value is better than a power density of $10 \mathrm{~mW} / \mathrm{m}^{2}$ of a miniature 
MFC using Shewanella oneidensis [15], or a power density of $12 \mathrm{~mW} / \mathrm{m}^{2}$ of a sediment microbial fuel cell [16], or the power density of a $14.6 \mathrm{~mW} / \mathrm{m}^{2}$ typical of an MFC [17], or a power density of $6.17 \mathrm{~mW} / \mathrm{m}^{2}$ of a BackyardNet TMFC [1]. The corresponding value of the current density obtained is $84 \mathrm{~mA} / \mathrm{m}^{2}$.

Table 3. Experimental output power at different load conditions for each specimen.

\begin{tabular}{cccccc}
\hline $\begin{array}{c}\text { Resistance } \\
(\mathbf{O h m})\end{array}$ & $\begin{array}{c}\text { Specimen } \\
\text { Power A }(\boldsymbol{\mu W})\end{array}$ & $\begin{array}{c}\text { Specimen } \\
\text { Power B }(\boldsymbol{\mu W})\end{array}$ & $\begin{array}{c}\text { Specimen } \\
\text { Power } \mathbf{C}(\boldsymbol{\mu W})\end{array}$ & $\begin{array}{c}\text { Specimen } \\
\text { Power } \mathbf{D}(\boldsymbol{\mu W})\end{array}$ & $\begin{array}{c}\text { Specimen } \\
\text { Power } \mathbf{E}(\boldsymbol{\mu W})\end{array}$ \\
\hline $\mathbf{4 7}$ & 0.12 & 3.93 & 7.36 & 12.15 & 57.53 \\
$\mathbf{1 0 0}$ & 0.17 & 5.85 & 15.6 & 18.06 & 92.16 \\
$\mathbf{2 2 0}$ & 0.25 & 7.9 & 21.64 & 26.53 & 147.27 \\
$\mathbf{4 7 0}$ & 0.28 & 9.86 & 32.6 & 37.12 & 299.2 \\
$\mathbf{1 0 0 0}$ & 0.30 & 10.44 & 34.04 & 41.33 & 310.24 \\
$\mathbf{1 0 , 0 0 0}$ & 0.07 & 1.36 & 6.82 & 12.6 & 53.87 \\
\hline
\end{tabular}

Figure 3. Comparison between the results of the output power (power curves) in the experimental stages.

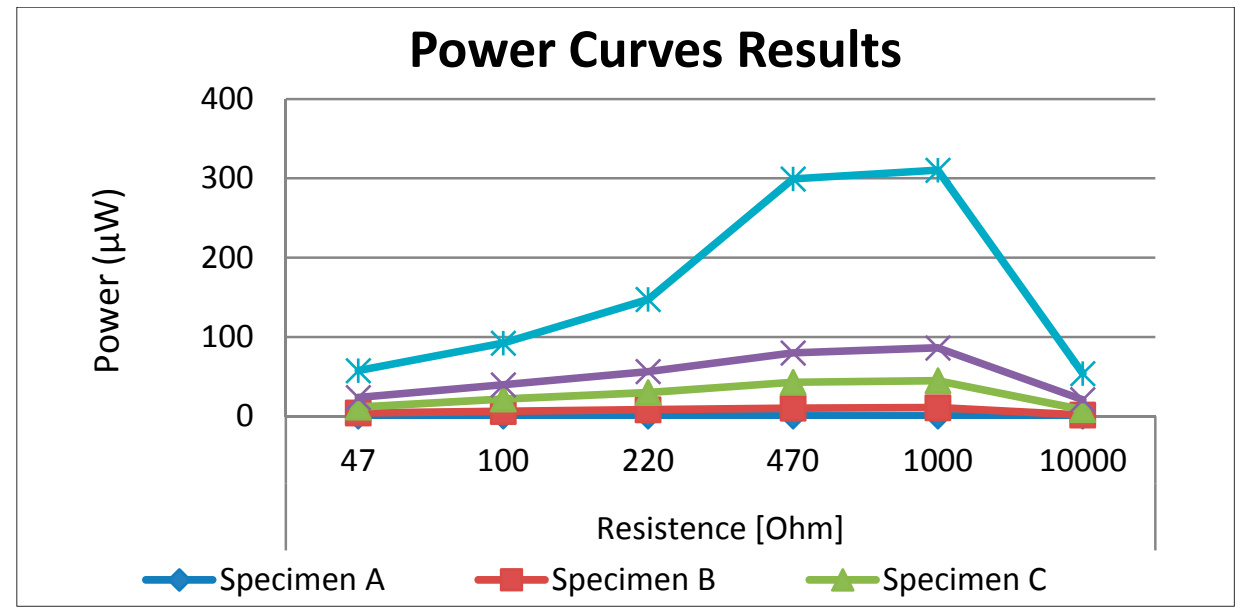

In comparison with benthic microbial fuel cells (BMFCs), which produce a typically power density of $30 \mathrm{~mW} / \mathrm{m}^{2}$, the TMFC used in this review obtained a better performance with $46.58 \mathrm{~mW} / \mathrm{m}^{2}$ [7].

\subsection{Comparison between Different Configurations of a Node}

In the previous sections, we investigated the TMFCs' performance, in order to assess the appropriateness of their use as power supplies for low voltage and low power electronic devices. Now, our main interest is to investigate if and how a TMFC could supply sufficient energy for adequately making the nodes of a wireless sensor network (WSN) work [18].

The following Table 4 presents the comparison, in terms of required DC current, between five different possible hardware configurations of a WSN node. The IEEE 802.15.4 standard communication protocol (like ZigBee protocol) is preferable to the IEEE 802.11 standard protocol, e.g., Wi-Fi, because it is more suitable for low-power personal area networks. Consequently, all transceivers compared in the table are limited to the IEEE 802.15.4 standard protocol.

The first configuration (C1) includes transceiver module XBee Series 2 by Digi, combined with a MC9S08Q32 free-scale microcontroller. The second configuration (C2) includes a transceiver XBeePro 
S2B by Digi that integrates the same previous free-scale microcontroller. The XBeePro S2B device shows a larger outdoor line-of-sight transmission range than XBee Series 2. Specifically, the XBeePro S2B series reaches $3200 \mathrm{~m}$ for the case of the U.S. variant or $1500 \mathrm{~m}$ for that of the international variant compared to $120 \mathrm{~m}$ for the Series 2, but requires more current for its functioning. The third and fourth configurations are based on RF modules made by the microchip industry. The third configuration (C3) includes the MRF24J40MA RF module combined with the PIC24F04KL100 low power microcontroller. The fourth configuration (C4) incorporates the MRF24XA RF module together with the same PIC24F04KL100 microcontroller. The fifth configuration includes SN260 modules by ST Microelectronics: a network processor that integrates a transceiver and the XAP2b Core microprocessor.

Since the TMFC, tested in this review, generates a maximum current of $557 \mu \mathrm{A}$, not enough to support what the WSN node requires, one needs to store energy during the time that the system is in standby mode. The mode of operation for energy storage remains until the energy reaches the amount required to support the data transmission. Therefore, we consider additional circuits for storing electrical charges, and Table 4 shows the duration of the minimum charge time at a constant current, assuming the charge is linear and normalized to the single bit transmitted, evaluated for each configuration. We consider a minimum throughput of $5 \mathrm{Kbps}$, typical for a standard configuration with five nodes, to calculate the minimum charge time required to transmit the single bit. The required current during transmission mode, and standby current, specified in the same Table 4, are the sum of currents absorbed from each component (transceiver, microcontroller, etc.) present in each of the five configurations. We specify that each of the components works at a voltage of $3.3 \mathrm{~V}$. Indeed, we had to raise the voltage from $0.68 \mathrm{~V}$, the best performance of a TMFC, to $3.3 \mathrm{~V}$ using a charging circuit, exploiting the properties of a capacitor. For the charging circuit, we will use a step-up DC-DC converter with coupled inductors for low input voltages $[19,20]$.

Table 4. Electrical consumption of a WSN transceiver: basic data comparison between five different configurations.

\begin{tabular}{cccccc}
\hline Configuration & $\begin{array}{c}\text { C1: } \\
\text { Xbee2 }\end{array}$ & $\begin{array}{c}\text { C2: } \\
\text { XbeePro S2B }\end{array}$ & $\begin{array}{c}\text { C3: } \\
\text { MRF24J40MA }\end{array}$ & $\begin{array}{c}\text { C4: } \\
\text { MRF24XA }\end{array}$ & $\begin{array}{c}\text { C5: } \\
\text { SN260 }\end{array}$ \\
\hline $\begin{array}{c}\text { Tx operating current } \\
\text { (max power output) }\end{array}$ & $48 \mathrm{~mA}$ & $233 \mathrm{~mA}$ & $23.3 \mathrm{~mA}$ & $25.3 \mathrm{~mA}$ & $35.5 \mathrm{~mA}$ \\
\hline Rx operating current & $38 \mathrm{~mA}$ & $62 \mathrm{~mA}$ & $19 \mathrm{~mA}$ & $13.5 \mathrm{~mA}$ & $35.3 \mathrm{~mA}$ \\
\hline Standby current & $1.5 \mu \mathrm{A}$ & $4 \mu \mathrm{A}$ & $2.03 \mu \mathrm{A}$ & $70 \mathrm{nA}$ & $1 \mu \mathrm{A}$ \\
\hline $\begin{array}{c}\text { Charge time } \\
\text { (single bit transmitted) }\end{array}$ & $0.01728 \mathrm{~s}$ & $0.0842 \mathrm{~s}$ & $0.00839 \mathrm{~s}$ & $0.00908 \mathrm{~s}$ & $0.01276 \mathrm{~s}$ \\
\hline $\begin{array}{c}\text { Outdoor RF } \\
\text { line-of-sight range }\end{array}$ & $120 \mathrm{~m}$ & $3200 \mathrm{~m}$ & $140 \mathrm{~m}$ & $140 \mathrm{~m}$ & $150 \mathrm{~m}$ \\
\hline
\end{tabular}

Considered the minimum number of sensor nodes needed by a suitable network for applications, like precision agriculture, the compromise for choosing the most suitable configuration is to try to limit the number of nodes, holding down costs. If the area to be covered is not very large, the nodes can be placed at a close distance, making the fourth configuration the most efficient, considering a low transmission rate. If, however, the time interval between two transmissions is decreased, while simultaneously increasing the number of acquired data to be transmitted, then the best configurations are, respectively, 
in the sequence $\mathrm{C} 3-\mathrm{C} 4-\mathrm{C} 5-\mathrm{C} 1$. Conversely, more powerful transmitters will be needed if the area to cover is extended, making the second configuration the more preferable one. However, it will require greater amounts of electrical current intensity for its functioning, making the system more complex.

\section{Conclusions}

In this work, we evaluated the possibility to supply power to a wireless sensor network through a TMFC, first obtaining an adequate amount of energy, operating on several factors that influence TMFCs' performance, such as $\mathrm{pH}$, temperature, humidity and the type of soil used. Then, we evaluated the applicability of TMFCs to provide energy to a wireless sensor network in different possible configurations. Concerning the factors that influence TMFCs' performance, we had seen that the $\mathrm{pH}$ of the medium plays a vital role in the applicability of the technology, and it should not fall below a threshold value of $\mathrm{pH}$ 6. The test showed that there are no large fluctuations in terms of energy production by varying the temperature in the mesophilic range. Ultimately the results, in terms of stability and energy efficiency, depend highly on the soil type; however, the $\mathrm{pH}$ and humidity level were seen to be basic parameters for its proper functioning.

In conclusion, we have determined that it is possible to exploit the energy supplied by the tested TMFCs for the functioning of a network node in each of the five configurations. Among the future developments, we consider the possibility of reducing consumption in terms of a power request from a node and to study the possibility of using a sediment microbial fuel cell. Imagining the development of a network for precision agriculture, the ideal would be to exploit crops whose soils have important factors, such as $\mathrm{pH}$, in a suitable range for TMFCs, as in the case of grapevine.

\section{Acknowledgments}

The authors would like to thank the following for their help: Lidieth Uribe and her research group, Keegan Cooke, Carlos Henriques, Carlos Corrales Alfaro, Tatiana Arguedas, Mariana Murillo, Arturo Valenciano Sequeira, Jonathan Masis Azofeifa and Michele Frazioli.

\section{Author Contributions}

The present paper is the result of the free, full and equal cooperation among all of the authors, who had the following roles and accomplished the following tasks. Andrea Pietrelli performed the research and wrote the paper. Andrea Micangeli, Project Coordinator, designed the research. Vincenzo Ferrara, Project Supervisor, supervised the scientific aspect of the whole paper contents. Alessandro Raffi, Project Participant, supported the activities related to the sustainability aspects of the work. All authors have read and approved the final manuscript.

\section{Conflicts of Interest}

The authors declare no conflict of interest. 


\section{References}

1. Cooke, K.G.; Gay, M.O.; Radachowsky, S.E.; Guzman, J.J.; Chiu, M.A. BackyardNet ${ }^{\mathrm{TM}}$ : Distributed Sensor Network Powered by Terrestrial Microbial Fuel Cell Technology. SPIE Proc. 2010, 7693, doi:10.1117/12.853930.

2. Zhao, F.; Slade, R.C.T.; Varcoe, J.R. Techniques for the study and development of microbial fuel cells: An electrochemical perspective. Chem. Soc. Rev. 2009, 38, 1926-1939.

3. Du, Z.; Li, H.; Gu, T. A state of the art review on microbial fuel cells: A promising technology for wastewater treatment and bioenergy. Biotechnol. Adv. 2007, 25, 464-482.

4. Bond, D.R.; Lovley, D.R. Electricity Production by Geobacter sulfurreducens Attached to Electrodes. Appl. Environ. Microbiol. 2003, 69, 1548-1555.

5. Kim, H.J.; Park, H.S.; Hyun, M.S.; Chang, I.S.; Kim, M.; Kim, B.H. A mediator-less microbial fuel cell using a metal reducing bacterium, Shewanella putrefaciens. Enzym. Microb. Technol. 2002, 30, $145-152$.

6. Gorby, Y.A.; Yanina, S.; McLean, J.S.; Rosso, K.M.; Moyles, D.; Dohnalkova, A.; Beveridge, T.J.; Chang, I.S.; Kim, B.H.; Kim, K.S.; et al. Electrically conductive bacterial nanowires produced by Shewanella oneidensis strain MR-1 and other microorganisms. Proc. Natl. Acad. Sci. USA 2006, 103, 11358-11363.

7. Guzman, J.J.; Cooke, K.G.; Gay, M.O.; Radachowsky, S.E.; Girguis, P.R.; Chiu, M.A. Benthic Microbial Fuel Cells: Long-Term Power Sources for Wireless Marine Sensor Networks. SPIE Proc. 2010, 7666, doi:10.1117/12.854896.

8. Schamphelaire, L.D.; van den Bossche, L.; Dang, H.S.; Höfte, M.; Boon, N.; Rabaey, K.; Verstraete, W. Microbial Fuel Cells Generating Electricity from Rhizodeposits of Rice Plants. Environ. Sci. Technol. 2008, 42, 3053-3058.

9. Borello, D.; Corsini, A.; Delibra, G.; Evangelisti, S.; Micangeli, A. Experimental and computational investigation of a new solar integrated collector storage system. Appl. Energy 2012, 97, 982-989.

10. Dell'Era, A.; Zuccari, F.; Santiangeli, A.; Fiori, C.; Micangeli, A.; Orecchini, F. Energy optimisation and layout of a membrane-free OSEC system for the hypochlorite self-production in Developing Countries. Energy Convers. Manag. 2013, 75, 446-452.

11. Micangeli, A.; Cataldo, M. Micro Hydro in Emergency Situations: A Sustainable Energy Solution at La Realidad (Chiapas, Mexico). In Handbook of Sustainable Engineering; Kauffman, J., Lee, K.M., Eds.; Springer: Heidelberg/Berlin, Germany, 2013; pp. 163-179.

12. Micangeli, A.; Michelangeli, E.; Naso, V. Sustainability after the thermal energy supply in emergency situations: The case study of Abruzzi Earthquake (Italy). Sustainability 2013, 5, 3513-3525.

13. Grego, S.; Micangeli, A.; Esposto, S. Water purification in the Middle East crisis: A survey on WTP and CU in Basrah (Iraq) area within a research and development program. Desalination 2004, 165, 73-79.

14. Micangeli, A.; Naso, V.; Michelangeli, E.; Matrisciano, A.; Farioli, F.; Belfiore, N.P. Attitudes toward Sustainability and Green Economy Issues Related to Some Students Learning Their Characteristics: A Preliminary Study. Sustainability 2014, 6, 3484-3503. 
15. Ringeisen, B.R.; Henderson, E.; Wu, P.K.; Pietron, J.; Ray, R.; Little, B.; Biffinger, J.C.; Jones-Meehan, J.M. High Power Density from a Miniature Microbial Fuel Cell Using Shewanella oneidensis DSP10. Environ. Sci. Technol. 2006, 40, 2629-2634.

16. Donovan, C.; Dewan, A.; Heo, D.; Beyenal, H. Batteryless, Wireless Sensor Powered by a Sediment Microbial Fuel Cell. Environ. Sci. Technol. 2008, 42, 8591-8596.

17. Logan, B.E.; Hamelers, B.; Rozendal, R.; Schröder, U.; Keller, J.; Freguia, S.; Aelterman, P.; Verstraete, W.; Rabaey, K. Microbial Fuel Cells: Methodology and Technology. Environ. Sci. Technol. 2006, 40, 5181-5192.

18. Knight, C.; Cavanagh, K.; Munnings, C.; Moore, T.; Cheng, K.; Kaksonen, A. Application of Microbial Fuel Cells to Power Sensor Networks for Ecological Monitoring. In Wireless Sensor Networks and Ecological Monitoring; Mukhopadhyay, S.C., Jiang, J.A., Eds.; Springer: Heidelberg/Berlin, Germany, 2013; pp. 151-178.

19. Degrenne, N.; Allard, B.; Buret, F.; Morel, F.; Adami, S.; Labrousse, D. Comparison of 3 Self-Starting Step-Up DC-DC Converter Topologies for Harvesting Energy from Low-Voltage and Low-Power Microbial Fuel Cells. In Proceedings of the 2011-2014th European Conference on Power Electronics and Applications (EPE 2011), Birmingham, AL, USA, 30 August-1 September 2011; pp. 1-10.

20. Pollak, M.; Mateu, L.; Spies, P. Step-Up DC-DC-Converter with coupled inductors for low input voltages. In Proceedings of PowerMEMS 2008 + microEMS 2008, Sendai, Japan, 9-12 November 2008; pp. 145-148.

(C) 2014 by the authors; licensee MDPI, Basel, Switzerland. This article is an open access article distributed under the terms and conditions of the Creative Commons Attribution license (http://creativecommons.org/licenses/by/4.0/). 